\title{
Hydrologic properties and structure of the Mozumi Fault, central Japan
}

\author{
Craig B. Forster, ${ }^{1}$ James P. Evans, ${ }^{2}$ Hidemi Tanaka, ${ }^{3}$ Ronald Jeffreys, ${ }^{2}$ and Tsuyoshi Nohara ${ }^{4}$ \\ Received 12 February 2002; revised 9 April 2002; accepted 4 June 2002; published 18 March 2003.
}

[1] Analyses of rocks from the Active Fault Survey Tunnel (AFST) provides insight into the structure and hydrogeology of the northeast-trending Mozumi-Sukenobu fault, an active strike-slip fault with 125 to $500 \mathrm{~m}$ of right-lateral slip in central Japan. Interlayered regions of sub-vertical permeability zones formed by cataclasis and slip on clayrich foliated zones. Core samples range from $10^{-19} \mathrm{~m}^{2}$ to almost $10^{-13} \mathrm{~m}^{2}$. CFC analyses of waters from the fault zone show that water entering the tunnel is $27-36$ years old, yielding a bulk fault permeability of $10^{-14}$ to $10^{-15} \mathrm{~m}^{2}$. The data support a fault zone model of a fluid-saturated, lowvelocity zone with a sharp velocity contrasting with the protolith. Pore-fluid pressures could build and dissipate in isolated high permeability pods 10 's -100 's $\mathrm{m}$ in dimension. INDEX TERMS: 8010 Structural Geology: Fractures and faults; 8045 Structural Geology: Role of fluids; 8025 Structural Geology: Mesoscopic fabrics; 8030 Structural Geology: Microstructures; 8020 Structural Geology: Mechanics. Citation: Forster, C. B., J. P. Evans, H. Tanaka, R. Jeffreys, and T. Nohara, Hydrologic properties and structure of the Mozumi Fault, central Japan, Geophys. Res. Lett., 30(5), 8010, doi:10.1029/ 2002GL014904, 2003.

\section{Introduction}

[2] Numerous geophysical, geologic, and hydrologic investigations indicate that fault zones impact the flow of fluids in the subsurface. The hydraulic structure of faults is important in examining precursor phenomena in earthquakes [Tsunogai and Wakita, 1995; King et al., 1995]; and the relationship between fluids and faulting [Blanpied et al., 1992; Chester et al., 1993]. Deep boreholes or tunnels provide insights into fault zone structures [Ohtani et al., 2000] which allows us to determine the composition, internal structure, and deformation processes of fault zones.

[3] The Active Fault Survey Tunnel (AFST) central Japan $[J N C, 1998]$ provides an opportunity to examine an active fault in an underground gallery. We present the results of laboratory permeability and porosity measurements, and chloroflourocarbon analyses to document the permeability of the fault-related rocks in an active fault zone.

[4] The AFST is a horizontal drift 480 -m-long, $\mathrm{N} 24^{\circ} \mathrm{W}$ trending cut through the Mozumi-Sukenobu fault, Gifu

\footnotetext{
${ }^{1}$ Department of Geology and Geophysics, University of Utah, Salt Lake City, UT, USA.

${ }^{2}$ Department of Geology, Utah State University, Logan, UT, USA.

${ }^{3}$ Department of Earth \& Planet. Science, Graduate school of Science, University of Tokyo, Tokyo, Japan.

${ }^{4}$ Tono Geoscience Center, Japan Nuclear Cycle Development Institute, Jorinji, Izumi, Tokishi Gifu, Japan.
}

Copyright 2003 by the American Geophysical Union. 0094-8276/03/2002GL014904\$05.00 prefecture, Japan. The Mozumi-Sukenobu fault system trends $\sim \mathrm{N} 40^{\circ} \mathrm{E}$, with 125 to $500 \mathrm{~m}$ of right lateral slip [Ando, 1998]. A low level of seismicity [Mikumo et al., 1988; Mikumo, 1990; Wada et al., 1990]. The tunnel cuts rocks of the Jurassic Tetori Group [Kano and Shimizu, 1992; Figure 1] which consists of immature pebble conglomerates, siltstones, thin organic-rich intervals, and sandstones.

[5] Detailed mapping of the drift walls before they were lined was conducted by Mitsui Mining and Smelting Co. geologists. The tunnel encountered 1-12-m-thick shale beds and $10-20$-m-thick sandstone beds cut by two zones of intense deformation (crush zones, Figure 1). Sub-vertical zones consist of clay gouge and breccia, low rock quality (Figure 2a), and reduced seismic velocities. Crush Zone A is $\sim 20 \mathrm{~m}$ wide within the tunnel and is interpreted to be the trace of the active Mozumi-Sukenobu fault. Crush Zone B is $\sim 65 \mathrm{~m}$ wide. Numerous small faults and clay-rich shear zones separate Crush Zones A and B (Figure 1).

[6] Rock sampling of the fault zone comes from three boreholes (Figure 1). Our samples come from Borehole 1, Borehole A, and Borehole 2. Core recovery was remarkably good.

\section{Characterization of Faulted Rocks}

[7] Protolith is comprised of thin-bedded, fine-grained siltstones, angular breccias, random fabric cataclasites, wellfoliated clay-rich shear zones, and black, organic-rich shear zones (Figure 2a). Deformation in the fault zone occurred by shearing in clay/calcite-rich regions, plastic deformation of calcite, brittle fracture and faulting, flow of calcite-clay mixtures, and reaction-enhanced dissolution of calcite. Samples tested for permeability represent dark siltstone protolith (sample BH1-50.1), random fabric breccia/clayrich cataclasites (samples BHA-128.3, 133 and 143.2), and highly altered clay-rich gouge (samples BHA-122.4 and 127.8).

\section{Drillcore Tested as a Function of Confining Pressure}

[8] Six drillcore samples (Boreholes 1 and A) (Figure 1) were tested by Terra Tek, Inc. to obtain values of permeability $(k)$ and porosity $(n)$ over a ranges of confining pressures of 2.8 to $62 \mathrm{MPa}$. Tests were performed using nitrogen gas and API Recommended Practice \# 40 for steady state (higher permeability samples) and transient (lower permeability samples) tests. The samples were dried at $120^{\circ} \mathrm{C}$ prior to testing. Pore pressures were atmospheric during the tests. Porosity is computed from measurements of both pore volume and grain volume. The nominal confining pressure $\left(P_{c}\right)$ at the tunnel depth of $300 \mathrm{~m}$ is 7.6 $\mathrm{MPa}$ (the reference lines in Figure 3). 


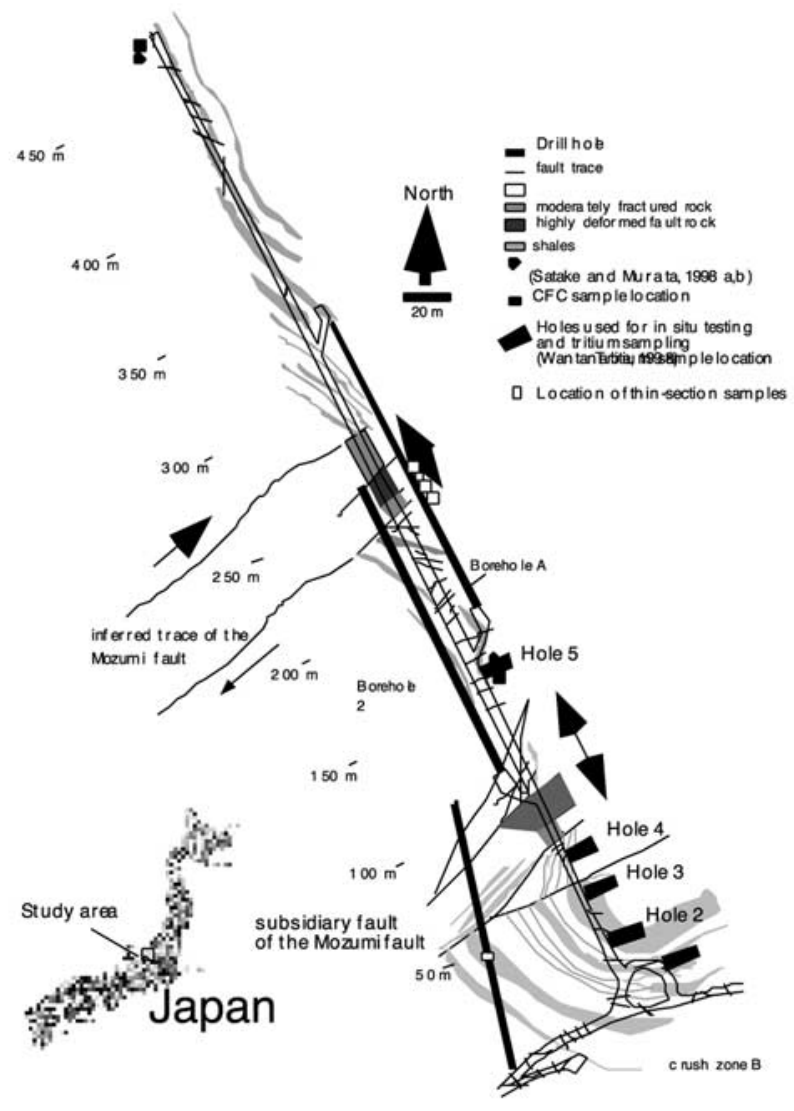

Figure 1. Simplified map of the Active Fault Survey Tunnel across the Mozumi Fault. Mapping conducted by $\mathrm{JNC}$ geologists indicates that the fault zone consists of subparallel slices of clay-rich gouge, breccia, and fractured rocks.

[9] With the exception of the shale breccia sample (BHA133). Log permeability $v s$ confining pressure $P_{c}$ (Figure 3a) are well-fitted with a relationship of $k=m P_{c}^{a}$ (Table 1). Although sample BHA-133 is best fit with an exponential

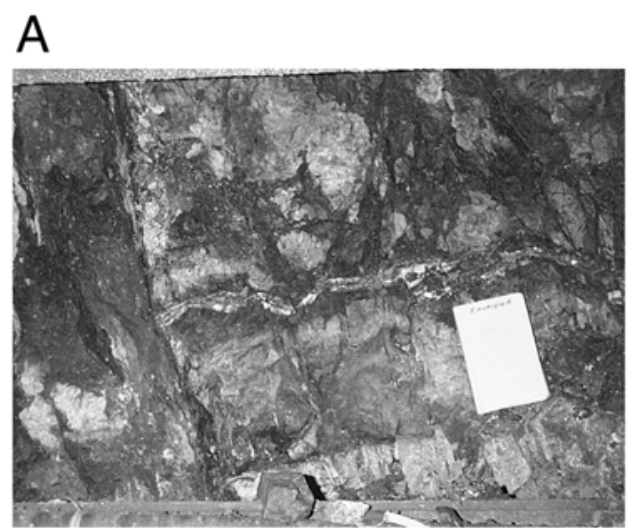

Figure 2. View of the fault zone within the Active Fault Survey Tunnel through the Mozumi fault. Field book is approximately $20 \mathrm{~cm}$ high. Narrow slip surface at left side of window consists of narrow clay-gouge surface; bedding is subhorizontal above the field book. a)

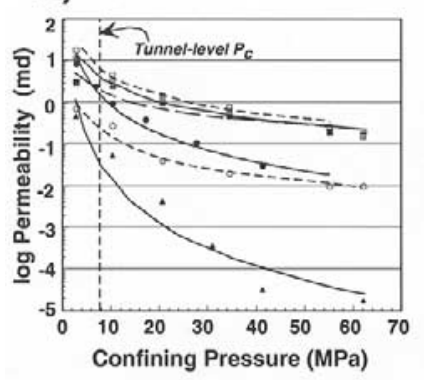

b)

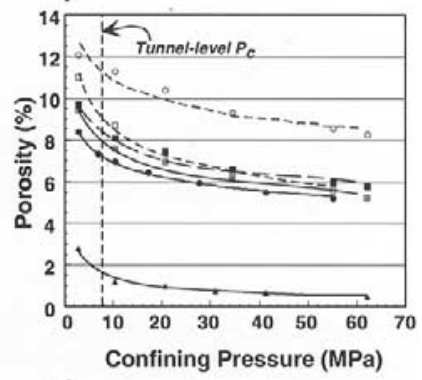

c)
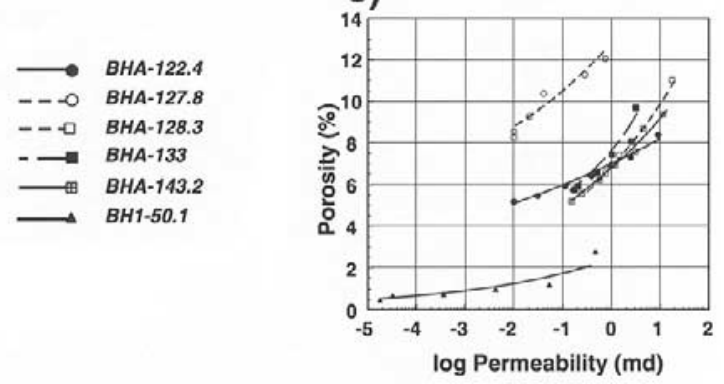

Figure 3. Results of permeability and porosity tests on drillcore samples obtained from the active fault survey tunnel cutting Mozumi-Sukenobu fault zone: (a) $\log$ permeability $k v s$ confining pressure $P_{c}$, (b) porosity $n v s$ confining pressure $P_{c}$, and (c) porosity $n v s \log$ permeability $k$. The nominal confining pressure at the tunnel level $(\sim 350$ $\mathrm{m}$ below ground surface) is $7.6 \mathrm{MPa}$.

relationship, we show a reasonable power law fit for comparison. All fault rock samples experience about a 1.5 order of magnitude decline in permeability as confining pressure is increased. The protolith shale sample (sample BH1-50.1) exhibits about 4.5 orders of magnitude decline in permeability (Figure 3a). This amplified response to changes in confining pressure results from its clay content and grain size similar to Evans et al. [1997] and Seront et al. [1998].

[10] Two breccia categories provide $k$ values of $10^{-17} \mathrm{~m}^{2}$ and $2 \times 10^{-16} \mathrm{~m}^{2}$ at elevated confining pressure. This suggests that fault zone anisotropy is caused by distinct contrasts in the permeability of fault breccia. Porosity $(n)$ for all breccia samples, except sample BHA-122.4, approaches a limiting value of 5 to $6 \%$ (Figure 3b). Sample BHA-122.4 approaches a limiting porosity of about $8 \%$.

[11] Porosity $v s$ confining pressure relationships are well fitted by $n=m P_{c}^{a}$ (Figure 3; Table 1). The groupings are similar to those found in Figure 3a. Responses of $k$ and $n$ to changes in confining pressure are reflected Figure $3 \mathrm{c}$. The results are well fitted with $k=m k^{a}$ (Table 1). The protolith shale sample (sample BH1-50.1) has the lowest $k$ and $n$ of all samples tested, and suffers the greatest decline in permeability as a function of increasing confining pressure. Most samples of shale and siltstone breccia yield tunnellevel permeability values that vary between $10^{-14}$ and $10^{-15} \mathrm{~m}^{2}$ (Figure 3a). The shale breccia with fine matrix yields values of porosity about 1.5 times greater, and permeability about one order of magnitude lower than the those of other breccia samples for each value of applied $P_{c}$. This shows that high porosities do not equate to high 
Table 1. Curve Fitting Results and Computed Values of Tunnel-Level $k$ and $n$

\begin{tabular}{|c|c|c|c|c|c|c|c|c|c|c|c|}
\hline \multirow[b]{2}{*}{ Sample } & \multicolumn{3}{|c|}{$k=m P_{c}^{a}$} & \multicolumn{3}{|c|}{$n=m P_{c}^{a}$} & \multicolumn{3}{|c|}{$n=m k^{a}$} & \multicolumn{2}{|c|}{ Tunnel-Level Values } \\
\hline & $m$ & $a$ & $\mathrm{R}$ & $m$ & $a$ & $\mathrm{R}$ & $m$ & $a$ & $\mathrm{R}$ & $k\left(\mathrm{~m}^{2}\right)$ & $\mathrm{n}(\%)$ \\
\hline BHA-122.4 & 148.6 & -2.25 & 0.98 & 9.97 & -0.159 & 1.00 & 7.00 & 0.070 & 0.99 & $1.6 \times 10^{-15}$ & 7.2 \\
\hline BHA-127.8 & 4.46 & -1.49 & 0.96 & 14.41 & -0.125 & 0.95 & 12.67 & 0.083 & 0.97 & $2.2 \times 10^{-16}$ & 11.1 \\
\hline BHA-128.3 & 88.22 & -1.39 & 0.99 & 14.14 & -0.221 & 0.99 & 6.903 & 0.159 & 1.00 & $5.3 \times 10^{-15}$ & 9.0 \\
\hline BHA-133 & 13.59 & -0.98 & 0.85 & 11.73 & -0.165 & 0.99 & 7.52 & 0.154 & 0.96 & $1.9 \times 10^{-15}$ & 8.4 \\
\hline BHA-143.2 & 57.27 & -1.35 & 0.99 & 11.49 & -0.181 & 0.99 & 6.68 & 0.133 & 1.00 & $3.7 \times 10^{-15}$ & 8.0 \\
\hline BH1-50.1 & 47.09 & -3.48 & 0.99 & 4.81 & -0.549 & 1.00 & 2.42 & 0.145 & 0.94 & $4 \times 10^{-17}$ & 1.6 \\
\hline
\end{tabular}

$\mathrm{R}=$ "Goodness of Fit"; $m, a=$ fitting parameters in Power Law relationships (e.g., $k=m P_{c}^{a}$ ).

permeabilities, due to the connectivity of the pore space in fine-grained rocks [Evans et al., 1997]. Clay-rich fault pods may be able to store fluid, but not allow flow.

\section{Chlorofluorocarbon (CFC) Estimates of Groundwater Age}

[12] Two sample sets of groundwater for CFC-age determinations were collected in clean 3/8-inch O.D. copper tubing sealed by cold welding the ends [Wilkowske, 1998]. Sample set MZ-164 was collected from the flowing Hole 5, and sample set MZ-480 was collected at the tunnel terminus (Figure 1). Sample analyses were performed with an analytical system similar to Wisegarver and Cline [1985]. Apparent recharge years were determined by computing the atmospheric concentration of CFCs that would be in equilibrium with the measured values at $5^{\circ} \mathrm{C}$ and a nominal groundwater recharge elevation of $1000 \mathrm{msl}$ above sea level. These atmospheric concentrations were compared with observed atmospheric values to assign a recharge year.

[13] Sample set MZ-164 shows a groundwater age of about 36 years. Sample set MZ-480 shows an age of about 27 years. These ages are consistent with the intermediate values of tritium concentration determined at the same locations by Satake et al. [this issue].

[14] Approximate bulk $k$ values parallel to the fault zone can be estimated at the $100 \mathrm{~m}$ scale using apparent CFC ages. Using transit time of 31 years, and an intermediate porosity of $9 \%$, bulk $k$ at the $100-\mathrm{m}$ scale is $3 \times 10^{-15} \mathrm{~m}^{2}$. This is remarkably similar to the in situ permeability test results $\left(2-20 \times 10^{-15} \mathrm{~m}^{2}\right)$ of Nohara et al. [this issue] where we collected Sample set MZ-164.

\section{Discussion and Conclusions}

[15] Our permeability values obtained from groundwater tracers and permeability testing of fault rocks range from $10^{-13} \mathrm{~m}^{2}$ to $10^{-19} \mathrm{~m}^{2}$ (Table 2). The largest values of permeability are estimated at length scales of 1 to $100 \mathrm{~m}$ associated with fractured rock in the fault zone and limited

Table 2. Summary of Fault Permeability Estimates

\begin{tabular}{lccc}
\hline \multicolumn{1}{c}{ Sample analysis } & Age & Permeability & \multicolumn{1}{c}{ Source } \\
\hline $\begin{array}{l}\text { CFC } \\
\text { analysis }\end{array}$ & $\begin{array}{l}27 \mathrm{yrs} \\
\text { Core-faulted sandstone }\end{array}$ & $10^{-13}-10^{-14} \mathrm{~m}^{2}$ & This study \\
$\begin{array}{l}\text { Core-shale gouge } \\
\text { In situ falling head tests }\end{array}$ & $10^{-14}-10^{-16} \mathrm{~m}^{2}$ & $\begin{array}{c}\text { This study } \\
\text { This study; } \\
\text { Watanabe et } \\
\text { al., this issue }\end{array}$ \\
& $10^{-16}-10^{-19} \mathrm{~m}^{2}$ & $\begin{array}{c}\text { Watanabe et al., } \\
\text { this issue }\end{array}$ \\
\hline
\end{tabular}

clay gouge content [Nohara et al., this issue]. Intermediate values of $k\left(10^{-14}\right.$ to $\left.10^{-16} \mathrm{~m}^{2}\right)$ are estimated at length scales of 0.01 to $1 \mathrm{~m}$ for fault breccia with intermediate, clay gouge content. The smallest $k$ values $\left(10^{-18}\right.$ to $10^{-19}$ $\mathrm{m}^{2}$ ) are estimated at the cm-scale from samples collected from clay-rich zones [see also Watanabe et al., this issue]. These results suggest faulting creates an interlayered sequence of sub-vertical, high, intermediate, and low $k$ zones.

[16] Both maximum and minimum values of $k$ are found within the fault zone. This structure fits the conceptual model of a conduit-barrier system [Caine et al., 1996]. The $k$ controlling flow in the plane of the fault is enhanced relative to the host rock while $k$ controlling flow across the fault is reduced relative to the host rock.

[17] Thin slivers of high permeability fault rocks (less than $10 \mathrm{~m}$ wide) likely transport the bulk of the subsurface flow. Distinct changes in geochemical regimes on each side of the fault are inferred from $\mathrm{Ca} / \mathrm{Na}$ values [Satake et al., this issue] and support the inference that water flowing parallel to, but on opposite sides of, the fault likely remains unmixed while moving towards the Takana River because the fault acts as a barrier to flow across the fault.

[18] The near-surface structure of several narrow slip surfaces embedded within breccia and cataclasite zones, some of which exhibit variable degrees of fluid-rock interactions, mimics that documented in studies of faults exhumed from 2-5 km deep [Chester et al., 1993; Gray et al., 1999; Jannsen et al., 1998; Schulz and Evans, 2000].

[19] The Mozumi-Sukenobu fault, where cut by the research tunnel, is a conduit-barrier system with bulk anisotropy for the fault zone (width of $\sim 200 \mathrm{~m}$ ) on the order of $10^{6}$. The fault zone comprises a complex structure with thin, sub-vertical slivers (cms to ms wide) of high- to low-permeability fault rocks. The fact that ongoing deformation is observed within the fault zone suggests that pore fluid pressures could be building and dissipating in high permeability pressure pods distributed within the fault zone.

[20] Acknowledgments. We thank the Japanese Nuclear Cycle Development Institute (JNC) for their financial and logistical support. We thank Drs. M. Yamakawa and S. Yamasaki. This work would not have been possible without the support and interest of Professor M. Ando who leads the research work at the Atotsugawa Fault system. Staff from the Mitsui Mining and Smelting Co., Ltd. allowed access to the Kamioka Mine and archived drillcore. Thanks to Hironobu Abe and Hidemi Osawa of JNC for assistance in the Mozumi tunnel and in examining JNC reports. Kip Solomon provided the equipment to collect CFC samples, determined the CFC concentrations, and computed the CFC ages. Thanks to Zoe Shipton for a review of an early draft of this paper. This effort was sponsored in part by the Air Force Office of Scientific Research, Air Force Material 
Command, USAF, under grant number F49620-95-1-0052, US-Japan Center of Utah. The U.S. Government is authorized to reproduce and distribute reprints for Governmental purposes notwithstanding any copyright notation thereon.

\section{References}

Ando, M., Overview and purpose of the active fault probe at the MozumiAtotsugawa fault system (Progress Report), Programs \& Abstracts, The International Workshop on Frontiers in Monitoring Science and Technology for Earthquake Environments, Toki and Kamioka, Japan, Nov. 1998, Japan Nuclear Cycle Development InstituteReport TW7400 98-001, 1998.

Blanpied, M. L., D. A. Lockner, and J. D. Byerlee, An earthquake mechanism based on rapid sealing of faults, Nature, 358, 574-576, 1992.

Caine, J. S., J. P. Evans, and C. B. Forster, Fault zone architecture and permeability structure, Geology, 24, 1025-1028, 1996.

Chester, F. M., J. P. Evans, and R. L. Biegel, Internal structure and weakening mechanisms of the San Andreas fault, J. Geophys. Res., 98, 771786, 1993.

Evans, J. P., C. B. Forster, and J. V. Goddard, Permeabilities of fault-related rocks and implications for fault-zone hydraulic structure, J. Struct. Geol., 19, 1393-1404, 1997.

Gray, D. R., C. Janssen, and Y. Vapnik, Deformation character and palaeofluid flow across a wrench fault within a Palaeozoic subduction-accretion system: Waratah Fault zone, southeastern Australia, J. Struct., 191-214, 1999.

Janssen, C., N. Laube, M. Bau, and D. R. Gray, Fluid regime in faulting deformation of the Waratah fault zone, Australia, as inferred from major and minor element analyses and stable isotopic signatures, Tectonophys., 294, 109-130, 1998.

JNC, Programs \& Abstracts, The International Workshop on Frontiers in Monitoring Science and Technology for Earthquake Environments, Toki and Kamioka, Japan, Nov. 1998. Japan Nuclear Cycle Development Institute Report TW7400 98-001, 1998.

JNC, in press, H12 Project to Establish Technical Basis for HLW Disposal in Japan: Supporting Report 1, to be published June, 2000.

Kano, T., and M. Shimizu, Mineral deposits and magmatism in the Hida and Hida marginal belts, central Japan, in Mineral deposits of Japan and the Philippines, edited by T. Urabe and A. Masahiro, 29th IGC field trip guidebook, pp. 101-141, Society of Resource Geology, Tokyo, 1992.

King, C. Y., N. Koizumi, and U. Kitagawa, Hydrogeochemical anomalies and the 1995 Kobe earthquake, Science, 269, 38-99, 1995.

Mikumo, T., H. Wada, and M. Koizumi, Seismotectonics of the Hida region, central Honshu, Japan, Tectonophys, 147, 95-119, 1988.

Mikumo, T., Temporal variations of seismic activity and some precursors before recent intraplate earthquakes in Southwest Japan. In: Proceedings of Conference XLVI; the 7th U.S.-Japan seminar on Earthquake prediction, U. S. Geological Survey Open-File Report. 85-92, 1990.
Nohara, T., H. Tanaka, K. Wantabe, N. Furukawa, and A. Takami, Hydrogeologic properties of host and fault rocks in the Mozumi-Sukenobu fault zone, to Geophys. Res. Lett., this issue.

Ohtani, T., N. Tomida, T. Highuchi, K. Fujimoto, H. Ito, and H. Tanaka, Fault rocks and past to recent fluid characteristics from the borehole survey of the Nojima fault ruptured in the 1995 Kobe earthquake, southwest Japan, J. Geophys. Res., 105, 16,161-16,171, 2000.

Satake, H., M. Murata, and H. Hayashi, Chemical characteristics of groundwater around the the Mozumi-Sukenobu fault and the implications for fault activity, Geophys. Res. Lett., this issue.

Schulz, S. E., and J. P. Evans, Mesoscopic structure of the Punchbowl fault, southern California and the geologic and geophysical structure of active strike-slip faults, J. Struct. Geol., 22, 913-930, 2000.

Seront, B., T.-F. Wong, J. S. Caine, C. B. Forster, R. L. Bruhn, and J. T. Fredrich, Laboratory characterization of hydromechanical properties of a seismogenic normal fault system, J. Struct. Geol., 20, 865-881, 1998.

Tsunogai, U., and H. Wakita, Precursory chemical changes in ground water: Kobe earthquake, Japan, Science, 269, 61-63, 1995.

Wada, H., T. Mikumo, M. Koizumi, Recent seismic activity in the northern Hida, Toyama Bay and Noto Peninsula regions, Kyoto Daigaku Bosai Kenkyujo Nenpo; Disaster Prevention Research Institute Annuals. 33 B-1; Pages 57-74, Kyoto University, Disaster Prevention Research Institute. Kyoto, Japan, 1990.

Watanabe, K., S. Aluwihare, C. C. Win, and T. Yoshizawa, Hydraulic anisotropy formed by the clay-rich part of the Mozumi-Sukenobu fault, to Geophys. Res. Lett., this issue.

Wilkowske, C. C., Chlorofluorocarbons as hydrologic and geochemical tracers in fractured shales and saprolite, Oak Ridge Reservation, Tennessee. M.S. thesis, Department of Geology and Geophysics, University of Utah, Salt Lake City, Utah, 1998.

Wisegarver, D. P., and J. D. Cline, Solubility of trichlorofluoromethane (F-11) and dichlorodifluoromethane (F-12) in seawater and its relationship to surface concentrations in the North Pacific, Deep-Sea Research, $32,97-106,1985$.

C. B. Forster, Department of Geology and Geophysics, University of Utah, 135 S. 1460 E. Salt Lake City, UT 84112-0111, USA. (cforster@) mines.utah.edu)

J. P. Evans, Department of Geology, Utah State University, Logan, UT 84322-4505, USA. (jpevans@cc.usu.edu)

H. Tanaka, Department of Earth \& Planet. Science, Graduate school of Science, University of Tokyo, Hongo 7-3-1, Bunkyo-ku, Tokyo 113-0033, Japan. (tanaka@eps.s.u-tokyo.ac.jp)

R. Jeffreys, Department of Geology, Utah State University, Logan, UT 84322-4505, USA.

T. Nohara, Tono Geoscience Center, Japan Nuclear Cycle Development Institute, Jorinji, Izumi, Tokishi Gifu, Japan. (nohara@tono.jnc.go.jp) 